ESSAY

\title{
Coping with the mystery of death
}

Previously published at www.cmaj.ca

$\mathrm{E}$ ncountering death is arguably our most difficult task as physicians. Questions that have long troubled humankind arise, the most obvious being: What awaits us when we die? Unfortunately, those with enough personal insight into the matter are dead and unable to enlighten the rest of us. Whether they smile knowingly down from a heavenly perch or slip into unconscious oblivion cannot be known while on this earth.

The three monotheistic religions treat death as a journey, at the end of which the traveller is rewarded for living a righteous life. Thomas More, who chose earthly death instead of eternal damnation, believed strongly that man should remember the coming judgment at death to instruct his behaviour in life.

Judgment and eternity, and indeed the very existence of God, provide great solace to many. However, consolation can also be found in a more scientific understanding of death. To use Bertrand Russell's words: "Even if the open windows of science at first make us shiver after the cozy indoor warmth of traditional humanizing myths, in the end the fresh air brings vigor, and the great spaces have splendor of their own."

As physicians, we are closely involved with the physical reality of death. We witness violent death following traumas, unexpected and tragic death in the pediatric and obstetric wards, high-volume death on the internal medicine and intensive care services. Our contact with death can be terrible, satisfying or seemingly merciful. We help comfort patients and their families in the moments surrounding death. This is mentally and emotionally taxing work, and there is rarely time to stop and think about the meaning of it all.

My recent experiences on the internal medicine service provided personal

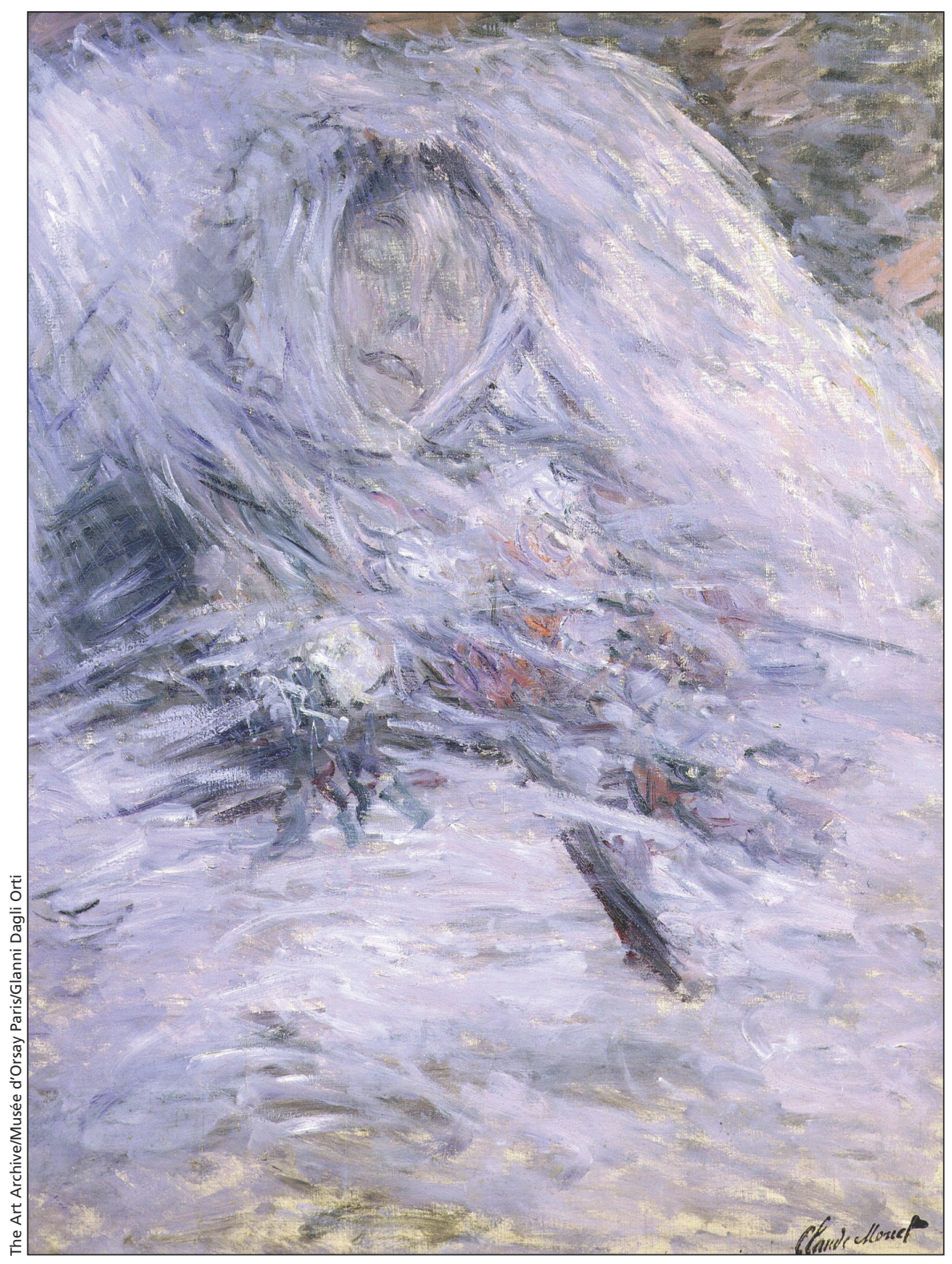

Claude Monet (1840-1926) Camille Monet sur son lit de mort, Camille Doncieux, 1847-79 (the artist's first wife on her deathbed) (1879).

contact with the dying experience of a number of patients. All were elderly with bulky medical histories - each one contributed to my own perception of death and dying.

Pronouncing my first patient alone allowed for my most intimate contact with the aftermath of death. My patient was an elderly man receiving palliative care for metastatic lung cancer. During our protracted relationship I learned about his interesting life. On most days, he had a smile or a joke to share. Like other physicians, I found the long amount of time spent caring for a dying patient was a source of both satisfaction and distress. ${ }^{2}$ When my patient died, he was comfortable and 
his family was present - I believe that his was a good death.

Standing alone beside his body, I was struck by the finality of death. Pallor mortis and algor mortis were both present; rigor mortis still waiting to pulseless wrist. Her advance directive had been dutifully established and there was no flourish of activity or calls for help — we sat quietly and watched her die. On her face I saw no pain or alarm. Life quietly slipped

\section{The philosopher David Hume observed that he feared the thought of oblivion at death no more than the idea of non- existence before birth.}

creep in. During previous pronouncements of death I had been accompanied by another living being to walk me through the steps: "Pupils fixed and dilated. No heart sounds. No breath sounds. No pulse."

Rationality could not fathom a way by which any remnant of this once vibrant man could transcend the solid walls of that hospital room. Strangely though, this disbelief in an afterlife was not accompanied by fear. I did not fear for my departed patient, for myself or for my loved ones. I am not alone. In his dying days in 1776, the Scottish philosopher David Hume observed that he feared the thought of oblivion at death no more than the idea of nonexistence before birth. ${ }^{3}$

If there is nothing inherent to fear in the aftermath of death, is there anything dreadful in the moment of death? Today we possess vastly superior amounts of knowledge about the universe and about our bodies than our contemporaries did short centuries ago. For many, "the fear of death is being replaced by the fear of dying." ${ }^{4}$ But the dying act is fleeting, often not witnessed.

Recently, chance allowed me to observe the exact moment of death. At an octogenarian patient's bedside, I explained how we would insert a nasogastric tube into her stomach. Moments before, she had been conversing with her family members, who had stepped out for the short procedure. With a nurse assisting me, we prepared to insert the tube. As we both watched her face, the patient suddenly stopped breathing. She turned grey and fell silent. I felt her away. The poignant memory of her dying instant cannot be described as peaceful, but she experienced no pain and in that moment of dying, there was no sign of fear. It was over before those of us watching were certain it had begun. The exact cause unclear, I printed the words "cardiac arrhyth- mia" on the top line of her death certificate, and went to try to explain to her family what had happened.

It would be dishonest to claim that no aspect of death and its aftermath is frightening - mystery remains. But the true sorrow is the loss of life, not the state of death or the act of dying.

\section{Scott D. Smith MSc MD \\ Department of Family Medicine \\ Queen's University \\ Kingston, Ont.}

\section{REFERENCES}

1. Russell B. What I Believe (1925) In: Dawkins R The God Delusion. New York (NY): Bantam Press; 2006. p. 354-5.

2. Redinbaugh EM, Sullivan AM, Block SD, et al. Doctors' emotional reactions to recent death of a patient: cross sectional study of hospital doctors. BMJ 2003;327:185.

3. Milne HM. Boswell's Edinburgh Journals, 1767 1786. Edinburgh (Scotland): Mercat Press; 2001. p. 256-9.

4. Smith R. Death, come closer. BMJ 2003;327:0-f.

\section{More humanities at cmaj.ca}

Look for online exclusive articles on the Humanities page at cmaj.ca.

Articulating the unthinkable: Dr. David A. Haughton's disturbing paintings of the stark reality of pediatric oncology are expressions of his personal grief.
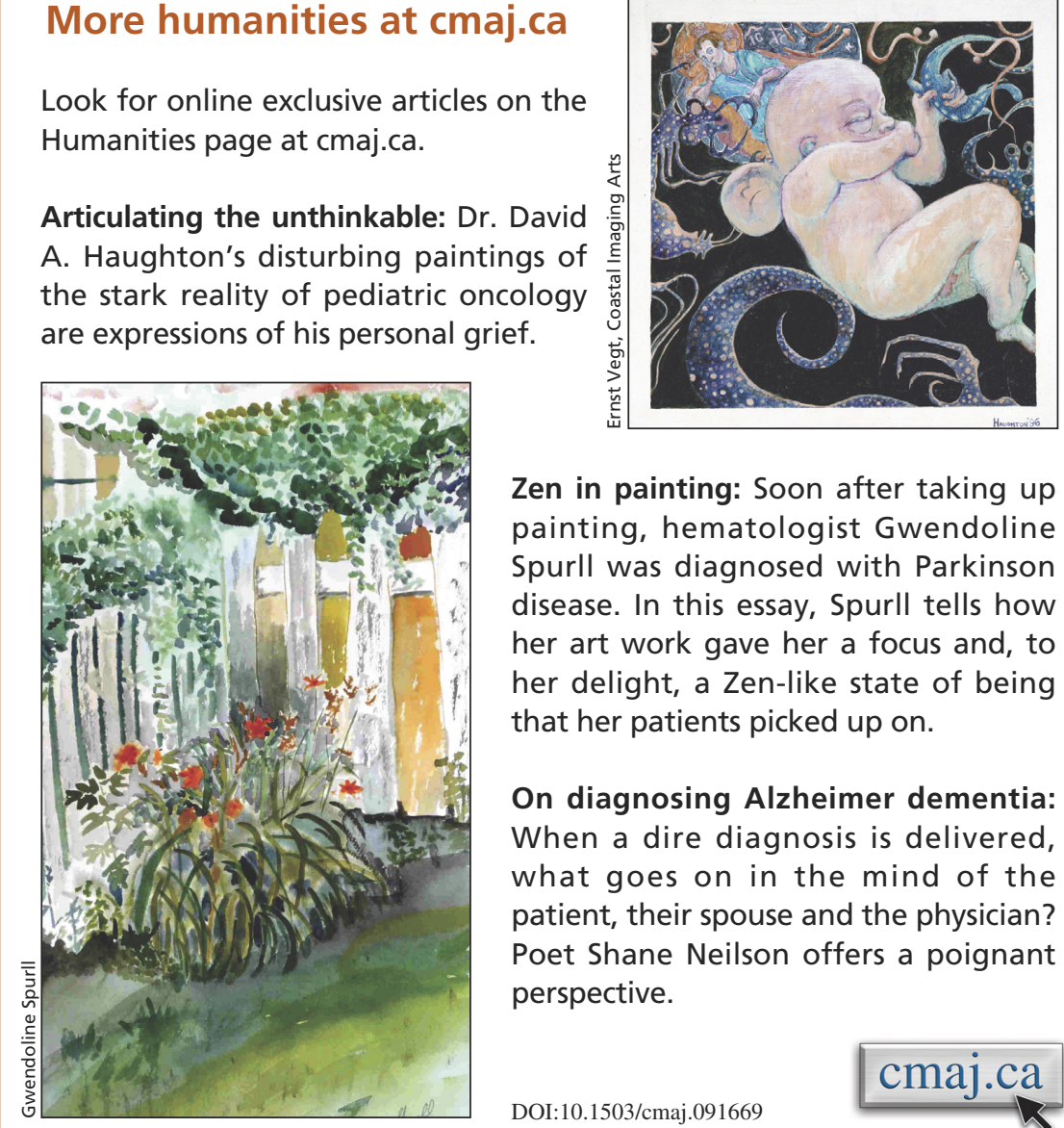

Zen in painting: Soon after taking up painting, hematologist Gwendoline Spurll was diagnosed with Parkinson disease. In this essay, Spurll tells how her art work gave her a focus and, to her delight, a Zen-like state of being that her patients picked up on.

On diagnosing Alzheimer dementia: When a dire diagnosis is delivered, what goes on in the mind of the patient, their spouse and the physician? Poet Shane Neilson offers a poignant perspective.

DOI:10.1503/cmaj.091669 cmaj.ca 